\title{
Order in NP conjuncts in spoken English and Japanese
}

\author{
Arne Lohmann ${ }^{a, *}$, Tayo Takada ${ }^{\mathrm{b}}$ \\ a Department of English, University of Vienna, Spitalgasse 2-4, 1090 Vienna, Austria \\ ${ }^{\mathrm{b}}$ Max Planck Institute for Psycholinguistics, Wundtlaan 1, 6525 XD Nijmegen, The Netherlands \\ Received 21 October 2013; received in revised form 18 September 2014; accepted 19 September 2014
}

Available online

\begin{abstract}
In the emerging field of cross-linguistic studies on language production, one particularly interesting line of inquiry is possible differences between English and Japanese in ordering words and phrases. Previous research gives rise to the idea that there is a difference in accessing meaning versus form during linearization between these two languages. This assumption is based on observations of language-specific effects of the length factor on the order of phrases (short-before-long in English, long-before-short in Japanese). We contribute to the cross-linguistic exploration of such differences by investigating the variables underlying the internal order of NP conjuncts in spoken English and Japanese. Our quantitative analysis shows that similar influences underlie the ordering process across the two languages. Thus we do not find evidence for the aforementioned difference in accessing meaning versus form with this syntactic phenomenon. With regard to length, Japanese also exhibits a short-before-long preference. However, this tendency is significantly weaker in Japanese than in English, which we explain through an attenuating influence of the typical Japanese phrase structure pattern on the universal effect of short phrases being more accessible. We propose that a similar interaction between entrenched long-before-short schemas and universal accessibility effects is responsible for the varying effects of length in Japanese. (c) 2014 Elsevier B.V. All rights reserved.
\end{abstract}

Keywords: Language production; Word/phrase order; Cross-linguistic; English; Japanese

\section{Introduction}

Recent research on language production has emphasized the need for cross-linguistic studies, particularly those involving typologically diverse languages (e.g. Jaeger and Norcliffe, 2009; Jaeger and Tily, 2011). In theories of language production most mechanisms are assumed to be universal, thus to not depend on the speaker's language. However, evidence for these mechanisms comes predominantly from the study of English and a few typologically related languages. While this trend seems to have changed recently (see e.g. Christianson and Ferreira, 2005; Ueno and Polinsky, 2009; Gennari et al., 2012), many questions regarding possible language(-type)-specific effects in language production remain unanswered.

An important area of study in this regard is cross-linguistic research on the linearization of syntactic constituents, and in particular the question of which factors influence the order of words and phrases. In this area a divergence has been observed between English and Japanese, as the length of phrases seems to influence linearization differently between the two languages. For Japanese it has been found that, with regard to the order of verbal arguments, speakers prefer long phrases before shorter ones (e.g. Yamashita and Chang, 2001; Yamashita, 2002), while English is well-known to exhibit the

\footnotetext{
* Corresponding author. Tel.: +4314277 42425.

E-mail address: arne.lohmann@univie.ac.at (A. Lohmann).
} 
reverse tendency (e.g. Hawkins, 1994; Arnold et al., 2000; Wasow, 2002). One explanation for this divergence is provided by distance minimization accounts which claim that speakers prefer to minimize the distance between verbs and their arguments, as shorter distances are correlated with processing ease (Hawkins, 1994, 2004; Gibson, 1998). These theories make divergent predictions for head-initial languages, e.g. English, as opposed to head-final languages, e.g. Japanese: In Japanese, the order of long-before-short leads to a short distance between the verb and its arguments, while the reverse is true of English (see Hawkins, 1994, 2004). ${ }^{1}$ However, this explanation has met with skepticism in language production research, as its general logic is based on constraints of working memory during sentence comprehension, and it is not clear how distance minimization as a mechanism can be implemented into incremental production models (Chang, 2009:375).

In language production research, the order of words and phrases is thought to be contingent on their respective accessibility. Those elements which are more easily accessible, i.e. which can be more easily retrieved from the lexicon and/or are formulated faster, occur early in syntagmatic strings (e.g. Bock, 1982). Since short constituents are more accessible in this sense, they occur in early positions. This explanation can of course only explain the English, but not the Japanese bias. Therefore, adjustments to the general idea of accessibility have been proposed to account for the above mentioned language-specific tendencies. Yamashita and Chang (2001) argue that Japanese speakers focus more strongly on the rich semantics of long phrases during production and therefore produce long phrases early. In contrast, to English speakers form-related properties are assumed to be more relevant, which is why they place short phrases in early positions. This explanation points to different processes in "accessing form vs. meaning in incremental processing" (Jaeger and Norcliffe, 2009:876) of the two languages, challenging the idea of universal accessibility effects during production (see also Tanaka et al., 2011a:124-125). However, it is not clear what mechanism is responsible for this difference or how it is to be implemented in current models of language production. While Yamashita and Chang's (2001) explanation implies fundamentally different influences underlying the linearization of constituents between the two languages, it should be noted that these potential differences are far from exhaustively explored. One reason for this is that most studies investigate linearization in only one of the two languages, and thus do not provide a true cross-linguistic comparison of comparable syntactic phenomena. In this paper we contribute to the further cross-linguistic exploration of influences on linearization between English and Japanese by investigating and comparing the factors that underlie the internal order of English and Japanese Noun Phrase conjuncts in spoken language. The relevant syntactic constructions are exemplified in (3) (3a and 3b are translation equivalents, examples taken from Tanaka et al., 2011b:321).
a. (the) boat and (the) fisherman
b. booto to ryooshi

NP conjuncts in English and Japanese are particularly relevant syntactic constructions for the exploration of ordering influences for several reasons. First of all, with an NP conjunct both constituents of the conjunct belong to the same argument of the verb. Therefore, this construction falls outside the scope of distance minimization accounts (see above), which solely predict the positioning of arguments with regard to the verb. Hence, in NP conjuncts it is possible to investigate whether the putative differences between the two languages in accessing meaning versus form can be found in a construction that is not influenced by preferences of ordering verbal arguments. Second, NP conjuncts constitute a syntactic construction which is immediately relevant for distinguishing between competing architectures of language

\footnotetext{
${ }^{1}$ These predictions can be exemplified by the phenomenon of Heavy NP shift in English, where the order of verbal arguments (marked by square brackets in the examples below) is variable, see the following alternative orderings are possible (examples from Hawkins, 2004:26):

(1) a. Mary gave [to Bill] [the book she had been searching for since last Christmas]

b. Mary gave [the book she had been searching for since last Christmas] [to Bill]

Hawkins' Minimize Domain account predicts the first sentence (the short-before-long order) to be preferred over the second, since fewer words need to be processed until the three immediate constituents of the verb phrase are recognized (Hawkins calls this the combinatorial domain). For Japanese the theory predicts long-before short to be preferred in constructions with two verbal arguments. This can be exemplified by the two possible orderings in a ditransitive construction (from Yamashita and Chang, 2001:B52):
}

(2) a. Masako-wa [shinbun-de shōkai-sarete-ita otoko-ni] [okashi-o] todoketa. Masako-TOP newspaper-INST introduced man-DAT cake-ACC delivered 'Masako delivered to the man who was introduced in the newspaper the cake.'

b. Masako-wa [okashi-o] [shinbun-de shōkai-sarete-ita otoko-ni] todoketa.

Masako-TOP man-DAT newspaper-INST introduced cake-ACc delivered

'Masako delivered the cake to the man who was introduced in the newspaper.'

With example (2a) (long-before-short) the combinatorial domain is shorter than in (2b), due to a minimized distance between the postpositions of the two phrases and the verb in final position. For more detailed information, see Hawkins (1994, 2004). 
production models, as order variation does not involve a change in grammatical function assignment. For example, in the sentences the lost hiker fought time and winter versus the lost hiker fought winter and time (example from Bock and Warren, 1985:53), both constituents of the conjunct belong to the object NP, irrespective of their order. Therefore, in NP conjuncts, linearization can be investigated without the influence of grammatical role assignment. Third, there is a general uncertainty with regard to which factors influence the internal order of NP conjuncts in English and Japanese, as conflicting results have been reported in previous research, and it is therefore unclear how this construction should be handled in theories of language production (see Branigan et al., 2008:186-187). ${ }^{2}$ The two latter points will be discussed in detail below (see section 2).

The remainder of this article is structured as follows: section 2 discusses the results of previous research on the ordering process in NP conjuncts and explains the relevance of this syntactic construction for language production models. In section 3 , we present the databases used and describe how we operationalized the variables that were tested. Section 4 elaborates on the statistical modeling process we carried out and reports the results of this analysis. We discuss, in section 5 , the results obtained and argue that the findings can be best explained by a largely similar linearization process between the two languages. Section 6 concludes the paper.

\section{Order in NP conjuncts in models of language production}

In the following we explain the relevance of NP conjuncts for theories of linearization and language production models and discuss previous research on the ordering process in this syntactic construction.

In research on language production, there is an ongoing discussion as to how the linearization of linguistic elements is best modeled and which influences underlie this process. While it is generally agreed upon that speakers prefer more accessible material in more prominent, usually string-initial positions, it is less clear how this process interacts with grammatical function assignment. NP conjuncts are a particularly relevant construction for this discussion, since in English it is one of the few syntactic constructions where a variation in order does not correlate with a variation in grammatical function assignment, in contrast to, for example, the alternation between active and passive voice or the dative alternation (see e.g. Bock and Warren, 1985). This is important as the discussion revolves around the question as to whether the process of assigning grammatical functions and the mere ordering of elements are subject to different influences (see e.g. Christianson and Ferreira, 2005:106-110; Jaeger and Norcliffe, 2009:868-871). This possible difference is related to two stages assumed to exist during language production, viz., the functional and the positional stage; both of which are part of the process called grammatical encoding (e.g. Bock and Levelt, 1994; Levelt, 1989).

During the functional stage, lemmas, which represent the meaning side of lexical entries, are assigned grammatical functions, e.g. the role of subject or direct object. In a language like English, whose word order is fairly rigid, this process already determines the order of many constituents of an utterance, since, for example, subjects almost always precede verbs and objects in active sentences. After this assignment, the linear order of wordforms, the form component of the lexical entries, is determined during the positional stage. Traditionally these two stages have been assumed to be subject to different influences. During the functional stage only conceptual/semantic information of words (or lemmas, to be precise) is available, therefore, this stage is susceptible only to conceptual influences. Then, during the positional stage, wordforms are linearized according to their so-called lexical accessibility, which pertains to form-related properties, such as the length of the to-be-ordered constituents. This difference in which variables influence the two stages has been termed "informational encapsulation" (Levelt, 1989:276). Evidence for this encapsulation comes from observed interactions of the variables with different syntactic constructions. It is in this context that NP conjuncts are relevant: Bock and Warren (1985) and McDonald et al. (1993) find that conceptually more accessible lemmas (those denoting more imageable or animate entities), are assigned higher grammatical functions (e.g. subject function), which then results in their occurrence in initial positions. Such a preference for early positions is not observable in NP conjuncts, where both constituents are assigned the same grammatical function. This is congruent with the assumption of informational encapsulation, as ordering within NP conjuncts happens at the positional stage and should therefore only be influenced by lexical accessibility, but not by conceptual factors.

However, the assumption of informational encapsulation has been called into question by evidence that conceptual factors may also directly influence word order without change in grammatical function assignment. An area of research relevant in this regard is studies on so-called irreversible binomials, also termed freezes, most of which are NP conjuncts, ${ }^{3}$ e.g. law and order. In contrast to the experimental work mentioned above, these studies show robust effects of conceptual influences, such as animacy contrasts, as in men and machines or people and things (Cooper and Ross, 1975:65). Further evidence against encapsulation comes from languages in which word order and grammatical function are not as

\footnotetext{
${ }^{2}$ See also Jaeger and Norcliffe (2009:870) on the importance of NP conjuncts in language production research.

${ }^{3} 65.7 \%$ of all binomials in Cooper and Ross (1975) are noun binomials.
} 
strongly correlated as in English, showing that conceptual factors influence word order even when grammatical function is controlled for, i.e., speakers prefer conceptually accessible entities preceding less accessible ones, even when these are not assigned higher grammatical functions. Branigan and Feleki (1999) show such effects for Greek, Prat-Sala and Branigan (2000) for Spanish, Kempen and Harbusch (2004) for German, Branigan et al. (2008) and Tanaka et al. (2011b) for Japanese, and Cai et al. (2012) for Chinese. In contrast, Christianson and Ferreira (2005) find that in Odawa, a free word order language, conceptual accessibility influences grammatical function assignment but not word order. In summary, most, but not all of the aforementioned studies provide evidence for conceptual effects on word order, in contrast to informational encapsulation. However, a direct effect on order does not rule out that grammatical function assignment is not affected as well, as found by Tanaka et al. (2011b) and Cai et al. (2012), who show that both processes are sensitive to variation in conceptual accessibility. Cai et al. (2012) conclude from this that there may only be one stage in grammatical encoding which is influenced by both forms of accessibility.

The upshot of the discussion above is that there is mixed evidence regarding the question of whether conceptual factors only influence order indirectly via grammatical role assignment, as in the traditional two-stage architecture, or whether there is also a direct influence of these factors on the order of linguistic elements, as in alternative accounts. The different predictions of the two accounts can be directly investigated in NP conjuncts as explained above. However, the evidence as to which factors underlie ordering in this syntactic construction is far from clear-cut. Let us at this point review results from previous research, for both English and Japanese NP conjuncts, more systematically.

As mentioned above, consonant with the assumption of informational encapsulation, some experimental studies report null results of conceptual factors (Bock and Warren, 1985; McDonald et al., 1993). In contrast, Kelly et al. (1986) and Onishi et al. (2008) report influences of the conceptual variable 'category typicality' on order in NP conjuncts. With this variable, however, it is currently unclear whether it should be regarded as an effect of conceptual or lexical accessibility (Onishi et al., 2008). Interestingly, the results for the influences of lexical factors on ordering in NP conjuncts are also elusive, more specifically for the length factor, which is especially relevant in the present context: McDonald et al. (1993) find no consistent effect of shorter phrases preceding longer ones and speculate that such effects may be confined to expressions that are used repeatedly, such as irreversible binomials (see above). Turning to experimental studies on Japanese, the results for ordering in NP conjuncts are similarly unclear. While Branigan et al. (2008) and Tanaka et al. (2011b) find that variation in animacy does influence grammatical function assignment and word order directly, there was no reliable effect of animacy on order in Japanese NP conjuncts; both report trends in the predicted direction which are not statistically significant. Branigan et al. (2008), therefore, speculate that NP conjuncts instantiate an exceptional syntactic construction in that "NP conjuncts are not processed incrementally like other phrases" (Branigan et al., 2008:187).

The inconclusive results of experimental studies on ordering in NP conjuncts stand in contrast to studies on order in English irreversible binomials (see above), which show that their order can be predicted from properties of the to-beordered lexemes of which many can be explained via accessibility differences between the two lexemes. In those studies both conceptual influences and influences pertaining to phonological form, e.g. a short-before-long contrast, are well evidenced (e.g. Cooper and Ross, 1975; Benor and Levy, 2006). To our knowledge there have been no studies on ordering in Japanese binomials to date.

In summary, the question of which influences underlie the ordering process in NP conjuncts is far from conclusively answered in either of the two languages (see also Branigan et al., 2008:186). It is the aim of this paper to address this question by tapping a new methodological resource, viz., corpus data of spoken language. Our goal is to explore whether the order in NP conjuncts is driven by conceptual and lexical factors, as would be expected if conceptual factors influenced order directly, or, in line with the hypothesis of informational encapsulation, only by form-related factors such as length. Most importantly, we aim to test whether these factors differ between English and Japanese, which may point to languagespecific linearization processes. Yamashita and Chang's (2001) explanation for the cross-linguistic differences implies a trade-off between the effects of semantic and formal properties of to-be-ordered constituents during linearization, where each language 'chooses' to focus on one or the other. At least two hypotheses can be derived from this assumption: Considering the effects of length (cf. Yamashita and Chang, 2001), it can be hypothesized that also in NP conjuncts Japanese speakers prefer a long-before-short order, while the opposite holds for English. A further hypothesis would be that generally semantic/conceptual influences have stronger effects on the internal order of Japanese NP conjuncts than on English NP conjuncts. The following analysis will test those influences through a multifactorial analysis of hypothesized ordering constraints.

\section{Data and operationalization of variables}

The empirical investigation of factors influencing the ordering process in NP conjuncts relies on corpus data of spoken English and Japanese. While there is a tradition of corpus-linguistic research on language production (see overview in Jaeger, 2010:50), this methodological approach has also met with criticism as to whether it may be suitable for the investigation of production phenomena. The main criticism of corpus data is that it is heterogeneous, meaning that many 
variables simultaneously influence the crucial variable(s) under investigation. In this respect, corpus data differs from experimental settings, because in experiments confounding variables can be controlled for through careful selection of stimuli. While this may pose a problem for disentangling particular effects in corpus data, it needs to be mentioned that through multifactorial modeling, confounding variables in corpus data can also be controlled for. The most important advantage of corpus data is that it is more naturalistic in better representing language 'as it is used' in comparison to potentially artificial settings in experiments. Therefore, we conclude, along with (Jaeger, 2010), that corpus-based approaches are "a desirable methodological addition" (Jaeger, 2010:26) to other methods in language production research (see also Yamashita et al., 2011:xi).

A further reason for using corpus data for the current investigation pertains to properties of the linguistic phenomenon in question. Recall that many experimental studies yielded null results with regard to ordering influences. However, McDonald et al. (1993:222) speculate that this does not necessarily mean that there are truly no effects on the ordering process. Rather, it may simply be the case that the effects in NP conjuncts are weaker than in other constructions (see also Branigan et al., 2008:186) and were not detected due to the small sample sizes used in many experimental studies. ${ }^{4}$ Corpus data allow for substantially larger samples, which consequently increases the possibility to detect existing influences. In statistical terms, a larger sample size increases the so-called power of quantitative analyses, which denotes the possibility of detecting an effect in a sample if it exists in the population (Aron et al., 2009:175-221).

In terms of the present investigation, we relied solely on spoken corpus data, excluding written-to-be spoken material, as the effects we wish to investigate should be strongest in language that does not involve much planning. For the English data, we chose the International Corpus of English (GB-edition), a 1,000,000 word corpus of spoken and written British English, and restricted ourselves to the corpus components containing unscripted speech ( 430,000 words). We utilized the ICE-GB's syntactic annotation to extract all NP conjuncts (NP and NP) from the corpus. For Japanese, we chose the Corpus of Spontaneous Japanese (CSJ), which contains 7.5 million words of spoken Japanese. We extracted all instances of the NP to NP construction from a selection of the CSJ that contains all dialogues (131,544 words) and parts of the monologues (3,115,302 words). ${ }^{5}$ Since the Japanese corpus we employed is still much larger than the English corpus, we created a random sample of the concordances which roughly matched the size of the English sample. We chose to concentrate on the coordinating conjunction and in English and to in Japanese, as these forms are close functional equivalents across the two languages in being the typical conjoining conjunctions (see Kuno, 1973:112-123; Martin, 1991:154-159). Furthermore, this choice renders our results most directly comparable to previous research, which also investigated NP conjuncts with these coordinators (Branigan et al., 2008; Tanaka et al., 2011b).

We then applied a number of criteria in weeding out the data. First of all repetitions such as years and years were excluded, as well as coordinations of names of individuals, e.g. Peter and Emily, and when these occurred as part of a larger expression, e.g. Secretary General Douglas Hogg, as their ordering may be influenced by idiosyncratic factors that are hard to measure. We did not, however, generally exclude proper nouns, so names of countries, places, etc. were kept for the empirical analysis. ${ }^{6}$ Additionally, coordinations consisting of more than two elements were excluded. Since we are interested in the factors underlying an on-line ordering process, we included only those cases where order was reversible. This resulted in the exclusion of conjuncts where the second NP was a semantically, more or less, empty extension, such as and things and and stuff. Moreover, cases where the conjunct was the name of a corporation/band/product/book, e.g. Guns and Roses or sensoo to heiwa 'War and Peace' were excluded, as these are practically irreversible. Irreversible binomials, such as law and order, or gen'in to kekka 'cause and effect' were systematically excluded. We carried out corpus searches of the British National Corpus (BNC) and the Balanced Corpus of Contemporary Written Japanese (a similarly sized general corpus of written Japanese), respectively to identify such cases: If one ordering made up $>90 \%$ of a given combination of NPs in the respective corpus and if the conjunct surpassed a frequency threshold of 10 per 100 million words (in both orders), the corresponding data points were excluded from the sample.

This filtering process resulted in the following samples for English and Japanese NP conjuncts respectively (Table 1). We then coded the NP conjuncts for a number of variables which have been suggested to influence their order, based on the psycholinguistic literature and the studies on irreversible binomials (see above). Taking into account variables from research on irreversible binomials seems justified, as it has been shown in previous research that those factors underlie order also in reversible cases (Mollin, 2012; Lohmann, 2014). As outlined above we are most interested in influences

\footnotetext{
${ }^{4}$ For example, due to the experimental design used in McDonald et al. (1993), a sentence recall experiment, only those data points where the order of constituents was shifted during recall were considered, resulting in e.g. only 61 data points in experiment 1 which enter the crucial analysis (see Table 1 in McDonald et al., 1993:200).

${ }^{5}$ For the monologues, we used solely the corpus part 'Simulated Public Speaking'. See http://www.ninjal.ac.jp/corpus_center/csj/misc/ preliminary/4.html for details of the corpus make-up of the CSJ.

${ }^{6}$ In response to a concern raised by an anonymous reviewer, we excluded all proper nouns from the two samples and conducted separate empirical analyses of these sub-samples. Leaving out proper nouns does not change the overall pattern of results, but only results in very slight changes in the coefficients of the statistical models (see section 4). We therefore kept proper nouns in the samples for the main analysis.
} 
Table 1

The two datasets.

\begin{tabular}{ll}
\hline Corpus & Sample size $(N)$ \\
\hline $\begin{array}{l}\text { International Corpus of English (GB-edition) } \\
\text { (spoken, unscripted part) }\end{array}$ & 808 \\
$\begin{array}{l}\text { Corpus of Spontaneous Japanese } \\
\text { (dialogues and monologues) }\end{array}$ & 861 \\
\hline
\end{tabular}

pertaining to either conceptual or lexical accessibility; however, other influences were also considered to obtain a maximally accurate model illustrating which factors underlie the internal order of conjuncts, and to control for potentially confounding influences. The following ordering constraints were tested in the two languages.

\subsection{Conceptual accessibility}

This variable refers to the aforementioned tendency that constituents denoting more accessible concepts precede those of lesser accessibility. A number of contrasts are subsumed within this variable, based on previous research. Frequently mentioned in the literature are the ordering biases animate before inanimate (the manager and the keys or ningen to kikai 'man and machine') (e.g. McDonald et al., 1993), and concrete before abstract (the body and the mind or aatisuto to kyoku 'the artist and the music') (e.g. Bock and Warren, 1985), which are also considered here. We furthermore considered conceptual contrasts mentioned in the literature on binomials, based on Cooper and Ross (1975:65-66) and Benor and Levy (2006:238). These are, prototype first (also category typicality) ${ }^{7}$ (apples and grapefruits or gitaa to beesu 'guitar and base'), basic level before subordinate/superordinate level (houses and buildings or eigo to beigo 'English and American English'), proximal before distal (Europe and America or kankoku to iran 'South Korea and Iran'), own before other ( $m y$ car and your car or nihonjin to gaikokujin 'Japanese people and foreigners'), ${ }^{8}$ and present generation before other (parents and children or otooto to ryooshin 'my little brother and my parents').

\subsection{Iconic sequencing}

This variable is frequently mentioned in the literature on irreversible binomials (see Malkiel, 1959; Benor and Levy, 2006), which is why it is considered here. It denotes the tendency of a certain order in extra-linguistic reality to be reflected in the order of linguistic constituents. Following Benor and Levy (2006:239-240), we interpreted it as referring to instances of temporal order, e.g. birth and death, the afternoon and the evening, but also numerical orders, as in the eighth and the ninth. Examples from our data are, March and April, the past and the future, gozen to gogo 'morning and afternoon', mukashi to ima 'past and present', ichi-i to ni-i 'first place and second place', sei to shi 'life and death'.

\subsection{Extralinguistic hierarchy}

This variable is one of the frequently mentioned ordering constraints in the studies on irreversible binomials (where it is often termed 'power', e.g. Benor and Levy, 2006). It refers to the tendency that if one of the constituents' referents is ranked higher in an extra-linguistic hierarchy, it precedes the lower ranked one. One well-evidenced reflection of this tendency is a male-first bias (Sambur, 1999; Wright et al., 2005), as in men and women or brother and sister. Additionally, other hierarchies may also yield effects, as in the president and the vice-president (Sambur, 1999; Benor and Levy, 2006). We considered this variable applicable to instances that demonstrate a difference in power between the two referents in

\footnotetext{
${ }^{7}$ The variable prototype first or category typicality has been the subject of debate in language production research, because, although a conceptual factor, in experiments it influenced order in NP conjuncts, but not in other constructions (Kelly et al., 1986; Onishi et al., 2008). Onishi et al. (2008) suggest that while prototypicality effects originate from the conceptual level and therefore from activation differences between lemmas, its true influence is on the level of lexical accessibility, as "conceptual structure mediates lexical accessibility" (Onishi et al., 2008:107). While this question cannot be addressed here, due to the unclear status of this variable, it was specially coded in the data to allow for its separate analysis. We thank an anonymous reviewer for drawing our attention to the special status of this variable.

${ }^{8}$ An anonymous reviewer asked whether the coordination of second and third person possessive pronouns, e.g. your car and his truck, fall within the scope of the contrast own before other. We considered own before other to apply only to cases in which one constituent denotes an entity which is the possession of the speaker, or denotes a group the speaker belongs to, as in the aforementioned examples. With regard to personal pronouns, this means that only first person was considered to instantiate the concept own, while second and third person were considered other. Therefore, second and third person examples were considered to be outside the scope of this constraint and were consequently coded 0 .
} 
this sense, including the mentioned gender bias. Examples from our data include the dean and the tutor, musuko to musume 'son and daughter', sensei to seito 'teacher and student'. Because of the pervasive deference to age in Japan, in the Japanese sample, we additionally considered older people to be ranked above younger people. This is reflected in the examples toshi totteru hoo to wakai hoo 'the older one and the younger one' and haha to imooto 'my mother and my younger sister' from our dataset. ${ }^{9}$

\subsection{Information status}

A well-known variable underlying linearization is the (pragmatic) information status of to-be-ordered constituents, i.e., the tendency that information already active in the discourse precedes information new to the discourse. Evidence for this effect on ordering in constructions other than NP conjuncts has been accumulated for English (e.g. Bock, 1977), as well as for Japanese (Ferreira and Yoshita, 2003). Differences in information status can be reflected in the linguistic form which is used to express the information in question: Information already active in the discourse can be expressed via pronouns, whereas information new to the discourse is typically encoded via a full lexical NP. Therefore, if one of the two constituents was a pronoun, while the other was a full lexical NP, we coded these data points as instantiating the aforementioned contrast. In the English data, we furthermore considered contrasts between the definite and indefinite article as reflecting a difference in givenness, as in the doorman and a visitor. Since differences in information status are not always reflected in the choice of linguistic form, we moreover checked whether the referent of one of the two NPs was mentioned in the preceding discourse (the 100 words preceding the NP conjunct), applying a methodology similar to Gries (2003). We also coded a whole sequence as given, if the exact same order of elements was produced in the preceding context.

\subsection{Length of phrases}

The question of whether and how the length of the phrases influences their ordering is of pivotal interest in the current context, as it is this variable for which diverging ordering tendencies have been observed in previous research (see above). For the English data we counted the number of syllables of the phrases making up the conjuncts. We then coded for every data point as to whether it instantiates a short-before-long, a long-before-short, or an equal length sequence. For instance, blood and adrenalin instantiates a short-before-long ordering, while education and training is an example of long-before-short. For the Japanese data we conducted two separate length measurements. First, we measured length based on the number of morae, because the mora is generally assumed to be the most central phonological unit in Japanese (e.g. Otake et al., 1993). Since the mora count is not directly comparable to the English results, however, we also conducted a syllable count of the Japanese dataset to have a common unit of analysis across the two languages. ${ }^{10}$ The mora and syllable count can differ if words feature coda nasals, long vowels, or geminates, and there are some cases where the two operationalizations yield different length preferences. In example (4) from our data, there is no difference in syllables but a short-before-long order in number of morae, and in example (5) the syllable count yields a long-before-short sequence, whereas when counting morae we observe the opposite pattern (where spaces mark syllable boundaries and dots mark mora boundaries).

(4) ki ka.i to ni.n ge.n

machine and people

'machine and man'

(5) chi shi ki to ke.i ke.n

knowledge and experience

'knowledge and experience'

\footnotetext{
${ }^{9}$ This possible effect of age on ordering and the tendency to prefer an order of 'present generation before other generation', which we subsumed under conceptual accessibility, may yield conflicting predictions. An example of this is otooto to ryooshin 'my little brother and my parents', in the Japanese sample, whose ordering adheres to the predictions of Conceptual Accessibility (see above), but violates the predictions of the variable Extralinguistic Hierarchy. In the English sample such conflicts did not occur. Since these two ordering tendencies are evaluated as two separate variables in the statistical models calculated, such conflicts do not pose a problem for the quantitative analysis of the results. See section 4 for details on the quantitative analysis.

${ }^{10}$ While the status of the syllable as a phonological unit in Japanese is controversial, Kubozono (1989) provides evidence for its psychological reality in the form of speech error data.
} 


\subsection{Frequency}

A further influence which has been attributed to accessibility is the frequency of words or phrases. It is a wellestablished finding that more frequent words are recognized more quickly in lexical decision tasks (Balota and Chumbley, 1984). Corresponding to their greater accessibility, it has been shown that higher frequency words precede those of lower frequency in irreversible binomials (Fenk-Oczlon, 1989). ${ }^{11}$ We operationalized this variable as the string frequency of each of the two NPs making up the conjunct, as it has been shown that language users are sensitive to this information (Arnon and Snider, 2010). Since an influence of string frequency has only been evidenced for strings of up to four words (4-grams) (Arnon and Snider, 2010; Tremblay and Baayen, 2010), we restricted its application to constituents up to that length. This operationalization captured $73.2 \%$ of the English data and $79.2 \%$ of the Japanese sample. We conducted Internet searches (of all .uk and .jp webpages, respectively), ${ }^{12}$ in order to obtain the string frequencies and then determined whether the NP conjuncts instantiate a high-frequency before low-frequency sequence or the reverse.

\section{Statistical modeling and results}

Every data point in the two samples was coded for the aforementioned predictor variables resulting in two data frames, one for each language sample. In coding the data, we treated each variable as predicting a certain ordering, e.g. for the variable frequency: high-frequency strings before low-frequency strings. The data were then coded to reflect whether the predicted ordering of each variable was adhered to, or violated. For the variable length, we used the sequence of shortbefore-long as the default prediction. We then fitted binomial logistic regression models to the data frames to assess the influence of the variables on the ordering process. The particular method applied involves intercept-less models, similar to Benor and Levy (2006). ${ }^{13}$ Regular binomial logistic regression (with intercept) is a widespread methodological resource for predicting choices with a binary outcome. However, in the present case this method cannot be applied, as there is no clear binary response variable. In general, binomial logistic regression requires the coding of the response variables into the two classes 'successes' and 'failures'. For example, with the choice between the two forms of the English comparative, e.g. prouder versus more proud, either the periphrastic form (with more), or the synthetic form (-er) can be assigned the value 'success' (usually coded 1) and the other the value 'failure' (usually coded 0). There is no analogous way of assigning these values with NP conjuncts, considering we can only observe a relative ordering of two noun phrases, e.g. the manager and the keys, but there are no two categories (successes versus failures) in which all data points may be assigned. In order to adapt the regression model to this situation, following Levy (in press), the response variable was treated as a 'dummy' variable invariably set to the value 1 , and thus always coded as a success. For the independent variables, data vectors were created, one for each variable mentioned above. Its values indicate whether the respective ordering variable was adhered to (1), was violated ( -1$)$, or did not apply (0). This coding process can be exemplified with the example the manager and the keys. In this example, the variable conceptual accessibility was coded 1 (=adhered to) since an NP denoting an animate referent precedes an NP denoting an inanimate referent. Additionally, considering the first NP is longer than the second one, the short-before-long variable was violated, which was hence coded $(-1)$. These vectors were then entered into a logistic regression analysis whose model equation is the following:

$$
\log \left(\frac{p}{1-p}\right)=\beta_{1} x_{1}+\beta_{2} x_{2}, \ldots+\beta_{k} x_{k}
$$

$x_{1-k}$ here refer to the values of the independent variables, and $\beta_{1-k}$ are real valued numbers (usually termed the coefficients), which indicate the weight of the respective variables. Note that there is no intercept in the model (usually $\alpha$ or $\beta_{0}$ ). Three regression models were fitted: one for the English data and two for the Japanese sample, one for each of the two different operationalizations of the length variable in that language (see above).

The results of the regression models including the values for the individual coefficients are given in Table 2. All predictor variables tested yield significant results for both languages, except for frequency and the syllable-based length variable in the second Japanese model. Because there is a non-significant tendency for more frequent strings to precede less frequent strings, which is in line with our predictions, we kept frequency as a predictor in the models, following suggestions for model fitting by Gelman and Hill (2007:69). ${ }^{14}$ As mentioned above, for Japanese two models were

\footnotetext{
11 The locus of the frequency effect in the Bock and Levelt (1994) model is the subject of debate. While Jescheniak and Levelt (1994) argue that frequency affects the wordform but not the lemma, Gahl (2008) takes issue with this claim, arguing that also the lemma is affected. Since this discussion is only tangential to our aims, we do not elaborate on it in detail here.

12 We used the Google Search Engine.

${ }^{13}$ See also Levy (in press: Chapter 6.8.4) for a detailed description.

${ }^{14}$ When frequency is omitted from the models, the coefficients and significance values of the remaining variables change only slightly.
} 
Table 2

Results of the regression analysis for the two samples.

\begin{tabular}{|c|c|c|c|c|c|c|}
\hline \multirow[t]{2}{*}{ Variable } & \multicolumn{3}{|c|}{ English NP conjuncts } & \multicolumn{3}{|c|}{ Japanese NP conjuncts } \\
\hline & Coefficient & Std. error & $p$ & Coefficient & Std. error & $p$ \\
\hline $\begin{array}{l}\text { Length } \\
\text { (Short > Long) }\end{array}$ & 0.63 & 0.09 & $<0.001$ & $\begin{array}{l}0.19 \\
(0.12)\end{array}$ & $\begin{array}{l}0.09 \\
(0.09)\end{array}$ & $\begin{array}{l}<0.05 \\
(0.17)\end{array}$ \\
\hline Frequency & 0.09 & 0.09 & 0.33 & $\begin{array}{l}0.06 \\
(0.07)\end{array}$ & $\begin{array}{l}0.09 \\
(0.09)\end{array}$ & $\begin{array}{l}0.53 \\
(0.41)\end{array}$ \\
\hline Information status & 0.79 & 0.15 & $<0.001$ & $\begin{array}{l}0.47 \\
(0.46)\end{array}$ & $\begin{array}{l}0.16 \\
(0.16)\end{array}$ & $\begin{array}{l}<0.01 \\
(<0.01)\end{array}$ \\
\hline Conceptual accessibility & 0.83 & 0.21 & $<0.001$ & $\begin{array}{l}0.86 \\
(0.87)\end{array}$ & $\begin{array}{l}0.16 \\
(0.16)\end{array}$ & $\begin{array}{l}<0.001 \\
(<0.001)\end{array}$ \\
\hline Extralinguistic hierarchy & 0.85 & 0.34 & $<0.05$ & $\begin{array}{l}1.27 \\
(1.22)\end{array}$ & $\begin{array}{l}0.24 \\
(0.24)\end{array}$ & $\begin{array}{l}<0.001 \\
(<0.001)\end{array}$ \\
\hline Iconic sequencing & 2.59 & 0.53 & $<0.001$ & $\begin{array}{l}2.23 \\
(2.23)\end{array}$ & $\begin{array}{l}0.32 \\
(0.32)\end{array}$ & $\begin{array}{l}<0.001 \\
(<0.001)\end{array}$ \\
\hline$N$ & & 808 & & & 861 & \\
\hline
\end{tabular}

calculated: The first values in Table 2 are the model results obtained when the variable length is based on a count of morae; the numbers given in parentheses refer to the model where the variable length is based on a syllable count.

The models' overall classification accuracy is $69.6 \%$ for the English data and $66.0 \%$ (65.0\%) for the Japanese data, which represent statistically significant improvements over null-models, which would achieve $50 \%$ accuracy through simply guessing the order of conjunct constituents. However, the values are much lower than those of a fully predictive model, which would predict $100 \%$ of all orderings correctly. We will return to this result in the general discussion below. The fact that the coefficients of all predictor variables have positive values indicates that all predictor variables influence ordering in the predicted direction, and this direction is the same across languages. Having coded all variables using the same ternary categorical coding (see above), we can directly compare the coefficient values to assess the relative effect size of the ordering variables. The conceptual, semantic variables turn out to have the strongest influence ${ }^{15}$ with iconic sequencing being the variable demonstrating the largest effect size. This means that the semantic predictors are only seldom violated. A look at the corresponding standard errors, however, reveals that these are relatively high, which means that the semantic variables are often inactive (and were therefore coded 0 ). Information status, length and the frequency of the NP yield relatively weaker effects (lower coefficient values), yet these influences affect a larger share of the data (lower standard error values). Frequency is the variable with the smallest effect size in both samples (and, as mentioned above, it is not statistically significant in either sample).

From a cross-linguistic perspective, the most conspicuous result is the similarity of the models across the two languages, as all factors yield similar influences in the two samples. Also the length factor, which has been at the center of the debate about possible differences between English and Japanese, influences ordering in the same direction in the two languages: For both English and Japanese NP conjuncts, a short-before-long preference is found. This tendency is statistically significant in the English model and also in the Japanese model which employs a mora count, but is not statistically significant $(p=0.17)$ in Japanese when counting syllables. This finding will be discussed in detail below.

In terms of direction of effects, there is no apparent difference between the languages. However, differences may exist on a more fine-grained level, viz., in the sizes of the effects. A way to test for such differences is to calculate the $95 \%$-confidence intervals for the individual coefficients in both models. The confidence intervals define a range in which the true population parameter of the coefficient lies with $95 \%$ certainty. If there is no overlap between the two confidence intervals for a given variable in the Japanese and the English model, this can be understood as a statistically significant difference in the size of effect between the two languages. Table 3 provides the $95 \%$-confidence intervals for all coefficients in the models.

Comparing the confidence intervals of the models across the two languages shows that the intervals overlap for five out of the six tested variables, viz., all predictor variables except length. This means that with regard to these influences, no

\footnotetext{
${ }^{15}$ One variable subsumed under the predictor conceptual accessibility was 'prototype first', which may have a special status among the conceptual variables, see Note 6 . We analyzed this variable separately and found a trend for the more prototypical entity to be mentioned first, which is in line with previous research (Kelly et al., 1986; Onishi et al., 2008). In the English sample this constraint was adhered to 8 times, while it was violated 4 times (binomial test, $p<0.05$ ). For Japanese, the results are $28: 11$ in favor of prototype first (binomial test, $p<0.01$ ). Since it is unclear how this variable influences ordering, it is important to point out that leaving out all data points affected by it does not change the general pattern of the results, as the variable conceptual accessibility remains statistically significant even without prototype first, with only slight changes to the corresponding regression coefficient (the coefficient in the model for the English sample is 0.90 , for the Japanese sample it is 0.85 ( 0.87 ), for a mora and syllable count, respectively).
} 
Table 3

The 95\%-confidence intervals of the two models' coefficient values.

\begin{tabular}{|c|c|c|}
\hline Variable & $\begin{array}{l}\text { English NP conjuncts } \\
95 \% \text {-Confidence interval }\end{array}$ & $\begin{array}{l}\text { Japanese NP conjuncts } \\
95 \% \text {-Confidence interval }\end{array}$ \\
\hline $\begin{array}{l}\text { Length } \\
\text { (Short > Long) }\end{array}$ & $0.44-0.82$ & $\begin{array}{l}0.02-0.37 \\
(-0.06-0.30)\end{array}$ \\
\hline Frequency & $-0.10-0.28$ & $\begin{array}{l}-0.12-0.23 \\
(-0.10-0.25)\end{array}$ \\
\hline Information status & $0.48-1.09$ & $\begin{array}{l}0.16-0.78 \\
(0.15-0.77)\end{array}$ \\
\hline Conceptual accessibility & $0.42-1.24$ & $\begin{array}{l}0.54-1.18 \\
(0.56-1.19)\end{array}$ \\
\hline Extralinguistic hierarchy & $0.17-1.54$ & $\begin{array}{l}0.79-1.75 \\
(0.74-1.70)\end{array}$ \\
\hline Iconic sequencing & $1.53-3.65$ & $\begin{array}{l}1.59-2.87 \\
(1.59-2.87)\end{array}$ \\
\hline
\end{tabular}

significant difference in size of effect could be detected. The only variable for which there is no overlap is the length factor, for which the coefficients between the two models are thus significantly different $(0.19$ [0.12] for Japanese and 0.63 for English). This difference indicates that the short-before-long preference is significantly stronger in the English sample than in the Japanese sample. This cross-linguistic difference holds irrespective of whether length is measured in number of morae or syllables in the Japanese data. Comparing the two measurements yields the result that the short-before-long tendency is weaker when length is measured in number of syllables (the coefficient for the morae-count is 0.20 compared to 0.13 for the syllables-count). This is mostly due to cases where the two NPs are of equal length when counting syllables, as there are a number of data points that do not differ in number of syllables, but in number of morae. The following bar plot provides a detailed view of the effects of the variable length in both languages and the two length measurements in Japanese (see Fig. 1).

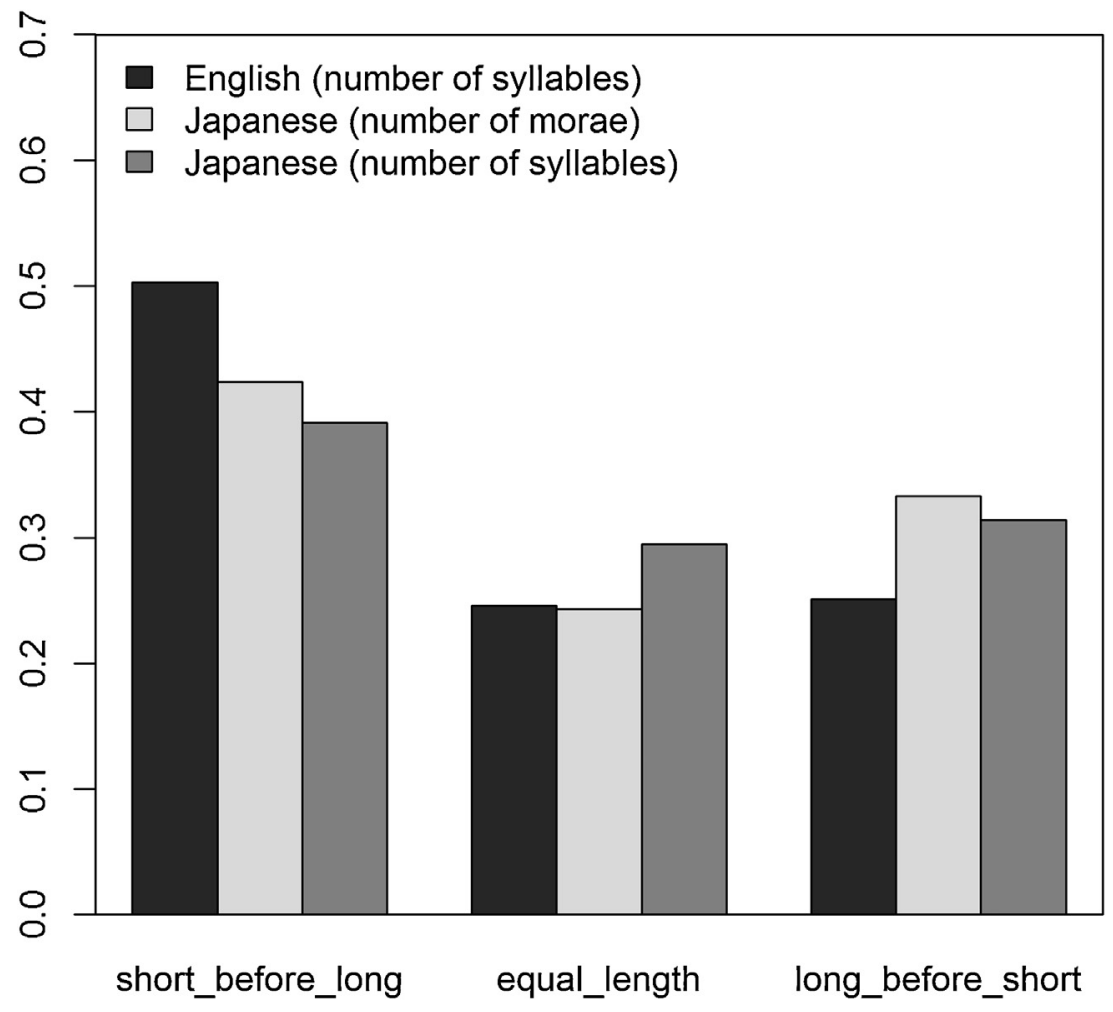

Fig. 1. Length and order in English and Japanese NP conjuncts. 
A comparison of the different ratios of short-before-long, long-before-short and equal length reveals a greater tolerance for a long-before-short ordering in Japanese NP conjuncts. While in English the difference in ratio between short-beforelong orderings and long-before-short orderings is $25.2 \%$ (50.3\% short-before-long orderings, $25.1 \%$ long-before-short orderings, $24.6 \%$ equal length), this difference is only $9.1 \%(7.7 \%)$ in Japanese $(42.4 \%$ [39.1\%] short-before-long orderings, $33.3 \%[31.4 \%]$ long-before-short orderings, $24.3 \%$ [29.5\%] equal length).

\section{Discussion}

\subsection{Overview}

The most important result obtained is that a variety of variables influence the ordering of phrases in NP conjuncts in both English and Japanese. These pertain to conceptual properties, as well as to the form of the to-be-ordered noun phrases. As many of the variables can be clearly related to differences in both lexical and conceptual accessibility between the phrases, ease of retrieval and/or formulation seems to be the main driving force underlying order in NP conjuncts, with largely the same effects across the two languages (the cross-linguistic differences are discussed in detail below). The findings tally with research on so-called irreversible binomials (e.g. Cooper and Ross, 1975, see above), which found influences of the same or similar variables on order. However, the findings stand in contrast with a number of empirical results obtained in previous research on NP conjuncts. Contrary to those studies that found no effects of conceptual factors on order (Bock and Warren, 1985; McDonald et al., 1993; Branigan et al., 2008; Tanaka et al., 2011b), we find that conceptual properties impact order, both in English and Japanese NP conjuncts. It needs to be mentioned here, however, that our results are not directly comparable to the experimental studies mentioned, as the variable conceptual accessibility in our analysis conflates a number of conceptual differences between the conjunct constituents, while experimental studies usually just study one narrowly defined contrast, e.g. differences in animacy. Given the heterogeneous nature of the corpus data we used, such a fine-grained analysis was not possible. Our results, therefore, do not allow for interpretations as to the effects of individual conceptual factors or differences between them (as discussed in e.g. Onishi et al., 2008). However, the overall pattern of results, with strong effects of the conceptual variables, gives us confidence that some conceptual properties, and thereby differences in lemma activation, do influence order in NP conjuncts.

With regard to properties of phonological form, we find an influence of length, in the direction of short-before-long, in contrast to experimental results by McDonald et al. (1993). Recall that due to the null results obtained in previous research on accessibility effects, Branigan et al. (2008) speculated that NP conjuncts may not be processed incrementally like other linearization phenomena. Our results indicate, however, that NP conjuncts are influenced by the same factors also at work in other linearization phenomena; there is thus no indication that NP conjuncts are processed differently.

A noteworthy result in this regard is the rather low predictive accuracy of the models calculated (see above), especially when compared to other linearization phenomena. For example, with the English dative alternation, much higher predictive accuracies of similar statistical models (about 90\% correct predictions) are obtained (e.g. Bresnan et al., 2007). A reason for this discrepancy could be a difference in strength of accessibility effects between these two syntactic constructions, with NP conjuncts being affected by them only to a lesser degree. Such an interpretation would be compatible with the one offered by Branigan et al. (2008:186), who concede that accessibility effects may not be nonexistent, but simply weaker in NP conjuncts. The possibility of a lesser strength of effects in NP conjuncts may in itself provide an explanation for the null results obtained in previous (experimental) research. In fact, both McDonald et al. (1993) and Tanaka et al. (2011b) find weak (non-significant) effects of animacy on order in NP conjuncts (see also Fig. 6 in Chang, 2009:386). In these studies the sample size of NP conjuncts was the same as for other linearization phenomena for which stronger influences may be assumed. Therefore, it is very well possible that the small samples resulted in a statistical power too low to detect these weaker influences.

\subsection{NP conjuncts in models of language production}

As mentioned in section 2, the question of which factors influence the order in NP conjuncts is of special relevance within language production research. Recall that in the two-stage model by Levelt (1989) and Bock and Levelt (1994), conceptual influences directly impact grammatical function assignment, but word order only indirectly, due to an assumed informational encapsulation of the individual stages. This model predicts a susceptibility of NP conjuncts to lexical accessibility effects, such as phonological length, but an immunity to conceptual influences. Our results are not compatible with these predictions, as both phonological length of the NPs and conceptual properties (most importantly those subsumed under conceptual accessibility) were found to influence the internal order of NP conjuncts. This is true for both languages investigated, as conceptual factors invariably influence order in both English and Japanese NP conjuncts. 
In contrast, the results obtained tally with findings from previous research on languages other than English, showing that differences in conceptual accessibility affect word order directly, independent of grammatical function assignment (e.g. Prat-Sala and Branigan, 2000; Cai et al., 2012; see section 2 for a detailed overview). Consequently the results are compatible with alternative models which postulate only one stage for grammatical function assignment and ordering, with both processes being influenced by the same accessibility effects (DeSmedt, 1990; Cai et al., 2012). The results, however, are not compatible with Tanaka et al.'s (2011b) model where both word order and grammatical function assignment are influenced by the same accessibility effects, but word order is mediated through grammatical function assignment, as their model predicts no influence of conceptual accessibility on order in NP conjuncts. It is worthy of note that in their experiment a (non-significant) tendency to prefer an animate before inanimate order in Japanese NP conjuncts was found, which is in line with possibly weaker, but still existent effects (see sections 2 and 5.1). We would like to suggest that such weaker effects on ordering in NP conjuncts as compared to other syntactic constructions could be explained through a single-stage model in which there are cumulative effects of accessibility on grammatical function assignment and on word order. Since the constituents of an NP conjunct do not differ with regard to grammatical function, effects would be assumed to be of lesser strength than in other syntactic constructions. Such a model could thus explain the weaker effects reported for ordering in NP conjuncts in previous research and also in the current article, as reflected in the low predictive accuracy of the statistical models. This explanation has the further advantage that NP conjuncts can still be explained by the same accessibility-based linearization principle, without having to assume that this syntactic construction is processed differently from others (cf. Branigan et al., 2008). Future research may find it worthwhile to empirically evaluate the predictions of such a model by comparing the influences on linearization across different syntactic constructions.

\subsection{The cross-linguistic dimension}

The result of a long-before-short bias in ordering arguments of the verb in certain constructions in Japanese gave rise to the assumption that there may be a difference in accessing meaning versus form between the two languages during language production. This possibility is based on the argument by Yamashita and Chang (2001) that long phrases have a richer semantics, which may render them conceptually more accessible. Thus, speakers of Japanese are held to focus more strongly on conceptual/semantic properties, while for speakers of English formal properties of words and phrases are more relevant (Jaeger and Norcliffe, 2009:876). However, our results for NP conjuncts show that both conceptual and formal properties yield the same influences on the ordering process in English and Japanese. Even the length factor influences order in the same direction. ${ }^{16}$ Thus, no difference which could be attributed to a general trade-off between meaning and form was found. At this level of generality, the results are much more compatible with an interpretation that assumes the same processes and mechanisms in accessing word and phrases during linearization in the two languages. Since the main result is that more accessible phrases are put in early positions, with similar effects across English and Japanese, our results demonstrate the importance of accessibility for linearization in a cross-linguistic context. It must be kept in mind, however, that we investigated only one syntactic construction here, thus it remains possible that further language-specific effects are found with other linearization phenomena.

While we observe an overall convergence of results between the two languages, there is one statistically significant difference. Both languages exhibit a preference for short-before-long in NP conjuncts, but this tendency is significantly stronger in English. It remains a possibility that this weaker influence of length in the Japanese sample is an effect of the "semantic richness" of long phrases (Yamashita and Chang, 2001:B53), which interacts with different sub-samples in our data. In Yamashita and Chang (2001), the long-versus-short contrast was between phrases that were modified through an embedded relative clause and those that were unmodified, and in Kondo and Yamashita (2011), length was measured in number of bunsetsu (a content word, often followed by a postposition). In the present study, however, modified, multi-word phrases and simple noun phrases were considered jointly, although differences in semantic richness may only be observable if phrases which differ in number of words or bunsetsu are coordinated. Longer, modified phrases may exhibit a tendency to precede shorter, unmodified phrases, in line with Yamashita and Chang's (2001) proposal, while NP conjuncts consisting of two unmodified phrases may adhere to a short-before-long bias. Depending on the make-up of the sample, the net result could then be the weaker short-before-long tendency we observe for Japanese. To explore this

\footnotetext{
${ }^{16}$ In Japanese, the short-before-long bias is stronger when measuring length in number of morae than in number of syllables (see Fig. 1), and only the mora count yields a statistically significant result. This is due to the fact that the syllable is the larger phonological unit. Using it to measure length differences fails to capture a number of cases of length differences on the moraic level and consequently results in more cases of equal length (see section 4). Since it has been shown that the mora is more central to Japanese speakers in segmenting words (Otake et al., 1993), we consider the mora count to be the more valid operationalization of length effects in Japanese. Therefore, we believe that the results can be interpreted as evidence for a short-before-long bias in Japanese NP conjuncts.
} 
possibility, we split the Japanese dataset into two sub-samples, one that contains only those NP conjuncts consisting of unmodified NPs $(n=555)$, and a second sample, in which at least one of the two NPs is a modified, multi-word NP $(n=331)$. With regard to the variable length, when measured in number of morae, both sub-samples exhibit a shortbefore-long tendency. In response to a comment by an anonymous reviewer, we furthermore conducted a bunsetsu-count of the whole sample of Japanese NP conjuncts, which crucially also yields a short-before-long tendency. ${ }^{17}$ It thus seems unlikely that the semantic richness of longer phrases is responsible for the weaker length effect observed in the Japanese data.

Rather than indirectly explaining the difference in effect size of the length factor via possible differences in the semantics of those phrases, we think that it can be more plausibly accounted for by taking into account the typical phrase structure of the two languages and the length relations of constituents therein. This explanation is similar to the one offered by Yoshida et al. (2010) for a different effect. In experiments, Yoshida et al. (2010) played sequences of tones of different lengths to English-learning and Japanese-learning infants of the age of 7-8 months. They found that the English infants segmented these tones into short-before-long patterns (iambs), while the Japanese infants exhibited a non-significant trend in the opposite direction (trochees). Yoshida et al. (2010) argue that this effect is due to a difference in phrase structure between the two languages to which the children are exposed. Because Japanese is a postpositional, head-final language, phrases exhibit the structure of an open-class, lexical element followed by a closed-class, grammatical element (a postposition). In English, which is head-initial, we observe the reverse order. Consider the following two translation equivalents which illustrate the contrast:
a. daigaku-ni
university-DAT
b. to university

The above phrase structure patterns produce many short-long phrases in English, while the opposite order can be observed in Japanese (Yoshida et al., 2010:360). As the findings by Yoshida et al. (2010) suggest, these patterns already influence infants when segmenting sounds, which thus gives rise to the assumption that they are well entrenched in adults. We would like to suggest that these language-specific phrase structure patterns can explain the differences in strength of the short-before-long tendency in NP conjuncts in the two languages. Yoshida et al. (2010) show that the patterns influence segmentation, a process relevant for language comprehension. However, it seems plausible that they may also influence language production and the linearization of constituents. While direct evidence for such an effect on production still needs to be obtained, the current results could be explained through such an influence interacting with universal accessibility effects. If we assume that short phrases are universally more accessible than long phrases, then the language-specific workings of the variable length may be explained through the interplay of this accessibility effect with the typical phrase structure patterns of the two languages. In English, both influences conspire, resulting in a strong short-before-long ordering tendency. In Japanese, however, where the typical phrase structure is a longer lexical element followed by a shorter postposition, this long-before-short pattern may yield an attenuating influence on the general shortbefore-long preference. Considering that the short-before-long bias also prevails in the Japanese data, the universal tendency to put shorter, more accessible phrases first seems to be the stronger influence. ${ }^{18}$ Further research on how exactly phrase structure patterns influence linearization processes and how they interact with other variables pertaining to the accessibility of to-be-ordered phrases is certainly necessary. Nevertheless, an explanation based on this interaction

\footnotetext{
17 The result of this calculation is that of the 243 cases of Japanese NP conjuncts that consist of phrases with different length in number of bunsetsu, 155 were short-before-long and 88 were long-before-short (binomial test, $p<0.001$ ). To further investigate the source of the length effect, we moreover analyzed separately the remaining data points, for which a bunsetsu-count yields no difference in length, and found that there was still a (weaker and statistically not significant) short-before-long bias in this sub-sample when measuring length in number of morae, with 236 cases being short-before-long and 214 instances long-before-short (binomial test, $p=0.21$ ). Based on these results it is hard to arrive at any firm conclusions as to which level is truly responsible for the length effect. One possible interpretation of the results is that both the number of bunsetsu and morae independently influence ordering decisions (in the direction of short-before-long). Investigating this possibility may be an interesting topic for future research.

${ }^{18}$ An anonymous reviewer remarked that there may be a mismatch between the linguistic experience of Japanese speakers and the factors that influence their production, as short-before-long has been shown to influence ordering, yet it is not uniformly found in the distributional patterns of the language. Based on previous research, we would however expect a correspondence between linguistic experience and production biases (Gennari et al., 2012). In response to this point, we would like to state that we do not think that there is actually such a mismatch. Due to shortbefore-long in some constructions (e.g. NP conjuncts) and long-before-short in others, we assume Japanese speakers to be exposed to varying distributions when it comes to the length of phrases. This less consistent experience of Japanese speakers, as compared to English speakers, is reflected in the weaker effect of length on ordering that we find, so that we actually see a correspondence between linguistic experience and production in Japanese. Interestingly, Yoshida et al.'s (2010) results tally with this interpretation, as they also find a less consistent effect of length with Japanese-learning infants, compared to the English-learning infants in their experiment.
} 
strikes us as a much less speculative account of the results obtained than explaining them indirectly via possible semantic differences which are hard to measure.

\subsection{Phrase length and linearization in Japanese}

With regard to the influences of the variable length on phrasal ordering, the results obtained here contrast with those obtained in previous research: we found a short-before-long preference holding in Japanese, in contrast to the longbefore-short tendency reported in other studies (e.g. Yamashita and Chang, 2001; Kondo and Yamashita, 2011). It thus seems that both ordering tendencies co-exist in Japanese. Hence, it cannot be stated without qualification that Japanese exhibits a preference to produce long phrases before short ones (cf. Jaeger and Norcliffe, 2009:875). This state of affairs raises two questions: First, which constructions are characterized by which ordering preference? Second, how can the coexistence of the two preferences be explained?

In approaching the first question, it is important to closely examine the phenomena analyzed in previous research, as well as the results obtained. All evidence for a long-before-short bias in Japanese comes from the ordering of arguments of the verb (Hawkins, 1994, 2004; Yamashita and Chang, 2001; Yamashita, 2002; Kondo and Yamashita, 2011). These findings point to a certain preference to move long, heavy arguments of the verb to early positions. This tendency could be explained through the principle of domain minimization (Hawkins, 2004), or through learning processes of languagespecific patterns (Chang, 2009). It cannot be adequately explained through a generally stronger focus on the rich semantics of long phrases and their possibly greater accessibility in Japanese, as such a general difference would then be expected to also result in a long-before-short preference in NP conjuncts. The scope of the long-before-short bias in ordering phrases thus seems to be restricted to the order of arguments of the verb. In that regard it is interesting to note that it has not been explored how pervasive the long-before-short tendency really is, as previous research focused on syntactic constructions which may not be very frequent in naturally occurring language. For example, in a large scale corpus study, Kondo and Yamashita (2011) report a long-before-short bias for ordering verbal arguments in ditransitive sentences and transitive sentences (optionally containing a locative phrase). In a sample of 80,000 clauses from corpus data, however, they find only 1107 instantiations of these sentence types. Since the crucial constructions thus make up only a small fraction of the corpus, the question of how representative the long-before-short tendency is of phrasal ordering in general remains at issue. Besides, to the best of our knowledge there are no studies on the effect of length on phrasal order beyond arguments of the verb, apart from the present paper. Therefore, we conclude that the empirical account of length effects on linearization is far from complete. Thus, only a tentative answer can be given to the first question raised above: A long-before-short order of phrases is preferred in linearizing arguments of the verb. Outside verbal constructions, the present study suggests that short-before-long prevails; however, more research is required to substantiate this assessment.

We turn now to the second question, namely, how the co-existence of the two preferences (short-before-long and longbefore-short) can be explained. We would like to suggest that these two patterns reflect the interaction of two ordering influences during language production: Universal accessibility effects, on the one hand, and the influence of entrenched language-specific patterns across different linguistic levels, on the other. This argument is similar to our explanation for the weaker short-before-long effect in Japanese NP conjuncts; however, it has a broader applicability. Turning first to accessibility, we believe that both English and Japanese speakers are subject to the same accessibility effects during production. Crucially, short words and phrases should be more accessible than long ones for speakers of both languages, in contrast to the suggestion by Yamashita and Chang (2001).

The second influence on order, we suggest, is that certain patterns existing across linguistic levels affect the ordering process. The latter argument takes up an explanation by Chang (2009:390) given for ordering tendencies in a connectionist, computational model. He states that a reason for the short-before-long effect in ordering verbal arguments in English may lie in the fact that the English main clause is characterized by a similar pattern, a short subject NP, followed by a typically longer predicate VP. Chang (2009:390) suggests that his connectionist model tries to find a similar representation across the clausal and the VP-internal level, which then results in the short-before-long preference. Taking this suggestion as a starting point, we propose that recurring patterns in a language on several linguistic levels may result in an abstract representation which may then influence linearization. In the case of Japanese, we find a long-before-short pattern across a number of linguistic levels: long lexical elements precede short postpositions within the phrase (see above, Yoshida et al., 2010). With regard to the ordering of clauses, long relative clauses precede short head nouns and long complement clauses almost invariably precede short main clauses. It thus seems plausible to assume that an abstract representation of the pattern long-before-short is formed. If there is an interaction of this pattern with a universal effect of short phrases being more accessible, the result may be either a short-before-long or a long-before-short sequence, depending on which of the two forces prevails.

The question that remains to be answered is how the prevalence of either one or the other factor can be accounted for. Considering that previous research found long-before-short in ordering verbal arguments, while we found 
short-before-long in a syntactic construction where both constituents belong to the same argument, it seems that the type of syntactic construction can explain the different results. We would furthermore like to suggest a possible second factor to explain this difference, viz., the amount of planning time available to the speaker. It has been shown in previous research that speakers adapt their planning scope to "pressures of different communicative contexts", which may lead to differences in how structural and lexical representations influence the production process (Konopka, 2012:3). In the present study we used solely unscripted, spoken data, thus we may assume that the utterances in our data were produced with a rather narrow planning window. It is likely that, in such situations, effects pertaining to the accessibility of individual words/constituents are strong, so that speakers are "greedily proceeding with whatever material is available first" (Jaeger and Norcliffe, 2009:869). In contrast to our data, there was less time pressure in most previous empirical research on phrasal order in Japanese: In the experimental study by Yamashita and Chang (2001), subjects had unlimited time to plan the order of constituents, and Hawkins' $(1994,2004)$ analysis is based on written data from Japanese novels. An exception is Kondo and Yamashita (2011), a study that yields a long-before-short bias, but, like the present paper, is based on data from the CSJ (Kondo and Yamashita, 2011). However, Kondo and Yamashita (2011) used only the corpus part of 'conference presentations', which represents a genre generally characterized by a great degree of advance planning. When a broader planning window is available to the language user, it is possible that the influence of abstract structural representations becomes stronger, and effects pertaining to the accessibility of individual words/constituents are mitigated. While the amount of planning is probably not the only factor influencing the interplay of the two forces we suggested, it is certainly worth investigating its role on linearization in future research.

The co-existence of different length distributions raises the more general question of why a long-before-short pattern should be formed in Japanese in the first place, if it is at odds with universal accessibility effects. While we cannot give a conclusive answer to that question, most of the patterns responsible for the length distribution seem to originate in Japanese OV word order and its left-branching structure. It is well known that the order of object and verb correlates with the order of many pairs of grammatical elements, such as adposition and NP, genitive and noun, relative clause and noun, and adverbial subordinator and clause (Dryer, 1992, 2007). For Japanese, these correlations result in a consistently leftbranching structure in which (usually longer) phrasal categories precede (usually shorter) non-phrasal ones. Some of these ordering patterns are explained by Hawkins (1994, 2009), who argues that a consistent long-before-short order in a left-branching OV language should be just as easy to process as a short-before-long order in a right-branching VO language, because both orderings keep the distance of phrasal heads to a minimum (see also Note 1). While this may explain the length distribution in OV languages like Japanese, one may still ask the general question whether OV would be harder to process than VO, as this order creates patterns which are incongruent with the demands of a purely accessibility-driven production mechanism. In fact, the argument that OV languages are potentially harder to process can be found in the literature, even if for other reasons. Ueno and Polinsky (2009) argue that, depending on the complexity and number of verbal arguments, it may be a processing disadvantage of OV languages to hold these arguments in working memory until the verb is encountered. However, more research on the differences in processing between OV and VO languages is needed to conclusively answer whether and how these affect processing ease. This line of research would ultimately be able to explore also the interaction of possible universal influences of accessibility with such differences.

\section{Conclusion}

Through a cross-linguistic investigation of spoken corpus data of English and Japanese, we find that the order of phrases within NP conjuncts is driven by largely the same ordering biases across the two languages. Thus, for this syntactic construction, we do not find evidence for the view expressed in the literature that for speakers of Japanese semantic properties may be more relevant in accessing phrases for linearization, while in English formal properties yield a stronger influence. Instead, we identify a case of convergence in which accessibility effects affect speakers of the two languages in similar ways. The only significant difference between the two languages that we find is a weaker shortbefore-long trend in the Japanese as compared to the English sample. We explain this difference as resulting from different phrase structure patterns in English and Japanese, which reinforce the universal short-before-long bias in English, while attenuating it in Japanese.

The results obtained have implications for the wider context of research on linearization in Japanese. We show that the long-before-short trend observed in a number of previous studies is not all pervasive. Taken together, a more complex picture emerges, as it seems that Japanese is characterized by both long-before-short and short-before-long sequences. In line with our explanation for the weaker short-before-long trend found in Japanese NP conjuncts, it seems plausible that this situation reflects the interplay between universal accessibility effects, which call for shorter phrases to be produced first, and an abstract representation of a long-before-short pattern, which is a recurring pattern found on several linguistic levels in Japanese.

On a methodological note, this paper demonstrates the benefits of a cross-linguistic comparison based on large samples of corpus data, as it allows for more detailed empirical analyses. In contrast to previous research, which merely 
compared general ordering tendencies of certain variables, e.g. short-before-long versus long-before-short, we also investigated differences in effect size, which revealed the weaker short-before-long bias in Japanese.

\section{Acknowledgements}

The second author would like to acknowledge that the lion's share of his work on this article was done during his MA studies at the University of Hamburg. Previous versions of this paper were presented at the 39th Annual Meeting of the LSA in Portland (OR) in 2012 and at the workshop on "Processing in Corpora" at the ICAME 34 in Santiago de Compostela in 2013. We thank the audiences of both events for their comments and suggestions. Furthermore, we would like to acknowledge our debt to Thomas Berg and Holger Diessel for their advice at several points during the investigation. All remaining errors and inaccuracies are our own.

\section{References}

Arnold, J.E., Lesongco, A., Wasow, T., Ginstrom, R., 2000. Heaviness vs. newness: the effects of structural complexity and discourse status on constituent ordering. Language 76 (1), 28-55.

Arnon, I., Snider, N., 2010. More than words: frequency effects for multi-word phrases. J. Mem. Lang. 62, 67-82.

Aron, A., Aron, E., Coups, E.J., 2009. Statistics for Psychology, 5th ed. Pearson Prentice Hall, Upper Saddle River, NJ.

Balota, D.A., Chumbley, J.I., 1984. Are lexical decisions a good measure of lexical access? The role of word frequency in the neglected decision stage. J. Exp. Psychol.: Hum. Percept. Perform. 10 (3), 340-357.

Benor, S.B., Levy, R., 2006. The chicken or the egg? A probabilistic analysis of English binomials. Language 82 (2), $233-278$.

Bock, K.J., 1977. The effect of a pragmatic presupposition on syntactic structure in question answering. J. Verbal Learn. Verbal Behav. 16, 723-734.

Bock, K.J., 1982. Towards a cognitive psychology of syntax: information processing contribution to sentence formulation. Psychol. Rev. 89, 1-47.

Bock, K.J., Levelt, W.J.M., 1994. Language production: grammatical encoding. In: Gernsbacher, M.A. (Ed.), Handbook of Psycholinguistics. Academic Press, London, pp. 945-984.

Bock, K., Warren, R., 1985. Conceptual accessibility and syntactic structure in sentence formulation. Cognition 21, 47-67.

Branigan, H.P., Feleki, E., 1999. Conceptual accessibility and serial order in Greek speech production. In: Hahn, M., Stoness, S.C. (Eds.), Proceedings of the 21st Conference of the Cognitive Science Society. Erlbaum, Mahwah, NJ, pp. 96-101.

Branigan, H.P., Pickering, M.J., Tanaka, M., 2008. Contributions of animacy to grammatical function assignment and word order during production. Lingua 118 (2), 172-189.

Bresnan, J.A., Cueni, A., Nikitina, T., Baayen, R.H., 2007. Predicting the dative alternation. In: Boume, G., Kraemer, I., Zwarts, J. (Eds.), Cognitive Foundations of Interpretation. Royal Netherlands Academy of Arts and Sciences, Amsterdam, pp. 69-94.

Cai, Z.G., Pickering, M.J., Branigan, H.P., 2012. Mapping concepts to syntax: evidence from structural priming in Mandarin Chinese. J. Mem. Lang. 66 (4), 833-849.

Chang, F., 2009. Learning to order words: a connectionist model of heavy NP shift and accessibility effects in Japanese and English. J. Mem. Lang. 61 (3), 374-397.

Christianson, K., Ferreira, F., 2005. Conceptual accessibility and sentence production in a free word order language (Odawa). Cognition 98 (2), 105-135.

Cooper, W.E., Ross, J., 1975. Word order. In: Grossman, R.E., San, L.J., Vance, T.J. (Eds.), Papers from the Parasession on Functionalism, April 17,1975 , pp. $63-111$.

DeSmedt, K.J.M.J., 1990. IPF: an incremental parallel formulator. In: Dale, R., Mellish, C. (Eds.), Cognitive Science Series Collections: vol. 4. Current Research in Natural Language Generation. Academic Press, London, pp. 167-192.

Dryer, M.S., 1992. The Greenbergian word order correlations. Language 68 (1), 81-138.

Dryer, M.S., 2007. Word order. In: Shopen, T. (Ed.), Language Typology and Syntactic Description: vol. I. Clause Structure. Cambridge University Press, Cambridge, pp. 61-131.

Fenk-Oczlon, G., 1989. Word frequency and word order in freezes. Linguistics 27, 517-556.

Ferreira, V.S., Yoshita, H., 2003. Given-new ordering effects on the production of scrambled sentences in Japanese. J. Psycholinguist. Res. 32 (6), 669-692.

Gahl, S., 2008. Time and thyme are not homophones: the effect of lemma frequency on word durations in spontaneous speech. Language 84 (3), 474-496.

Gelman, A., Hill, J., 2007. Data Analysis Using Regression and Multilevel/Hierarchical Models (1. publ.). Analytical Methods for Social Research. Cambridge University Press, Cambridge.

Gennari, S.P., Mirković, J., MacDonald, M.C., 2012. Animacy and competition in relative clause production: a cross-linguistic investigation. Cogn. Psychol. 65 (2), 141-176.

Gibson, E., 1998. Linguistic complexity: locality of syntactic dependencies. Cognition 68, 1-76.

Gries, S.T., 2003. Multifactorial Analysis in Corpus Linguistics. A Study of Particle Placement. Continuum, London.

Hawkins, J.A., 1994. A Performance Theory of Order and Constituency. Cambridge Studies in Linguistics, vol. 73. Cambridge University Press, Cambridge.

Hawkins, J.A., 2004. Efficiency and Complexity in Grammars. Oxford University Press, Oxford.

Hawkins, J.A., 2009. Language universals and the performance-grammar correspondence hypothesis. In: Christiansen, M.H., Collins, C., Edelman, S. (Eds.), Language Universals. Oxford University Press, Oxford, pp. 54-79.

Jaeger, F., 2010. Redundancy and reduction: speakers manage syntactic information density. Cogn. Psychol. 61, 23-62. 
Jaeger, F.T., Norcliffe, E.J., 2009. The cross-linguistic study of sentence production. Lang. Linguist. Compass 3 (4), 866-887.

Jaeger, F.T., Tily, H., 2011. Language processing complexity and communicative efficiency. WIRE: Cogn. Sci. 2 (3), 323-335.

Jescheniak, J.D., Levelt, W.J.M., 1994. Word frequency effects in speech production: retrieval of syntactic information and of phonological form. J. Exp. Psychol.: Learn. Mem. Cogn. 20, 824-843.

Kelly, M.H., Bock, K., Keil, F.C., 1986. Prototypicality in a linguistic context: effects on sentence structure. J. Mem. Lang. 25 (1), 59-74.

Kempen, G., Harbusch, K., 2004. A corpus study into word order variation in German subordinate clauses: animacy affects linearization independently of grammatical function assignment. In: Pechmann, T., Habel, C. (Eds.), Multidisciplinary Approaches to Language Production. Mouton de Gruyter, Berlin, pp. 173-181.

Kondo, T., Yamashita, H., 2011. Why speakers produce scrambled sentences: an analysis of a spoken language corpus in Japanese. In: Yamashita, H., Hirose, Y., Packard, J.L. (Eds.), Processing and Producing Head-Final Structures. Springer, New York, pp. $195-217$.

Konopka, A.E., 2012. Planning ahead: how recent experience with structures and words changes the scope of linguistic planning. J. Mem. Lang. 66 (1), 143-162.

Kubozono, H., 1989. The mora and syllable structure in Japanese: evidence from speech errors. Lang. Speech 32, $249-278$.

Kuno, S., 1973. The Structure of the Japanese Language. MIT Press, Cambridge, MA.

Levelt, W.J., 1989. Speaking: From Intention to Articulation. MIT Press, Cambridge, MA.

Levy, R., in press. Probabilistic Models in the Study of Language. MIT Press, Cambridge, MA (available at: http://idiom.ucsd.edu/ rlevy/ pmsl_textbook/text.html).

Lohmann, A., 2014. English Co-ordinate Constructions - A Processing Perspective on Constituent Order [Studies in English Language]. Cambridge University Press, Cambridge.

Malkiel, Y., 1959. Studies in irreversible binomials. Lingua 8, 113-160.

Martin, S.E., 1991. A Reference Grammar of Japanese: A Complete Guide to the Grammar and Syntax of the Japanese Language. Tuttle, Rutland, VT.

McDonald, J.L., Bock, K., Kelly, M.H., 1993. Word and world order: semantic, phonological, and metrical determinants of serial position. Cogn. Psychol. 25, 188-230.

Mollin, S., 2012. Revisiting binomial order in English: ordering constraints and reversibility. English Lang. Linguist. 16 (1), $81-103$.

Onishi, K.H., Murphy, G.L., Bock, K., 2008. Prototypicality in sentence production. Cogn. Psychol. 56 (2), 103-141.

Otake, T., Hatano, G., Cutler, A., Mehler, J., 1993. Mora or syllable? Speech segmentation in Japanese. J. Mem. Lang. 32 (2), $258-278$.

Prat-Sala, M., Branigan, H.P., 2000. Discourse constraints on syntactic processing in language production: a cross-linguistic study in English and Spanish. J. Mem. Lang. 42, 168-182.

Sambur, M., 1999. Factors that Influence Word Ordering of Conjunctive Phrases Containing a Male and a Female Name (unpublished paper). Available for download at: bespin.stwing.upenn.edu/ upsych/Perspectives/1999/sambur.htm.

Tanaka, M., Branigan, H.P., Pickering, M.J., 2011. The production of head-initial and head-final languages. In: Yamashita, H., Hirose, Y., Packard, J.L. (Eds.), Processing and Producing Head-Final Structures. Springer, New York, pp. 113-129.

Tanaka, M., Branigan, H.P., McLean, J.F., Pickering, M.J., 2011. Conceptual influences on word order and voice in sentence production: evidence from Japanese. J. Mem. Lang. 65, 318-330.

Tremblay, A., Baayen, R.H., 2010. Holistic processing of regular four-word sequences: a behavioral and ERP study of the effects of structure, frequency, and probability on immediate free recall. In: Wood, D. (Ed.), Perspectives on Formulaic Language. Acquisition and Communication. Continuum, London, pp. 151-173.

Ueno, M., Polinsky, M., 2009. Does headedness affect processing? A new look at the VO-OV contrast. J. Linguist. 45, 675-710.

Wasow, T., 2002. Postverbal Behavior. CSLI Publications, Stanford, CA.

Wright, S.K., Hay, J., Bent, T., 2005. Ladies first? Phonology, frequency, and the naming conspiracy. Linguistics 43 (3), $531-561$.

Yamashita, H., 2002. Scrambled sentences in Japanese: linguistic properties and motivations for production. Text 22 (4), $597-633$.

Yamashita, H., Chang, F., 2001. "Long before short" preference in the production of a head-final language. Cognition 81, B45-B55.

Yamashita, H., Hirose, Y., Packard, J.L., 2011. Head-direction and its effect on comprehension and production. In: Yamashita, H., Hirose, Y., Packard, J.L. (Eds.), Processing and Producing Head-Final Structures. Springer, New York, pp. xii-xiv.

Yoshida, K.A., Iversen, J.R., Patel, A.P., Mazuka, R., Nito, H., Gervain, J., 2010. The development of perceptual grouping biases in infancy: a Japanese-English cross-linguistic study. Cognition 115, 356-361. 